\title{
Effect of Participatory Forest Management (PFM) on Local Community Livelihood in Case of Bale Highlands, South East Ethiopia
}

\author{
*Umer Abdela Alemayehu Wudineh Abdulfata Abdu \\ Madda Walabu University, Bale Robe, Ethiopia
}

\begin{abstract}
Natural forests and their biodiversity have a high importance for the worldwide ecosystem goods and services for the support of livelihoods. Despite the great actual and potential socio-economic and ecological benefits derived from the forest resources in Ethiopia, PFM can sustain the natural resource and the livelihoods at once. FM stakeholders supposed to enjoy some benefits in terms of household opportunities to meet their basic needs. However the government devoted limited right as community does not supposed to make any decision about forest, not enjoying high value benefits and the voice of participants in terms of what to generate from the forest is dictated by experts. This study intended to examine the effect of PFM on local community livelihood. Exploratory and descriptive research methods were applied in selected areas and the roles of Participatory forest management contribution to local livelihood explored. Semi-structured questionnaire, key informant interview and focus group discussion were used for the purpose of socio economic study. Both qualitative and quantitative data were collected from 304 household and one focus group discussion and key informant interview(KII) consisting 12 and 8 members respectively. The collected of livelho-od contribution of PFM was analyzed using Microsoft excel software and SPSS 20version. The used Paired-t-test and chi-square test analysis of the incomes derived from different forest products before and after PFM as well as between members and non members of PFM revealed a significant difference $(\mathrm{p}<0.05)$. Generally the study showed PFM have slightly contributed to the livelihoods of the forest adjacent community. From study result concepts Introduction of improved sheep breeds, Organizing or strengthen saving and credit scheme, use of improved plant and animal varieties of locally adaptable and Promotion of agroforestry and plantations in homesteads was recommended.
\end{abstract}

Keywords: Forest Status, Effect, Livelihood and Participatory Forest Management

DOI: $10.7176 / \mathrm{JRDM} / 72-01$

Publication date: January $31^{\text {st }} 2021$

\section{INTRODUCTION}

Natural forests and their biodiversity have a high importance for the worldwide eco-systems in offering the rural poor with manifold ecosystem goods and services for the support of livelihoods. Local people often depend on nearby natural resources products and services to meet basic human needs of food, cloth and shelter, and other additional needs of development. For instance about 240 million people live in forested regions and an estimated 350 million people rely on forests as safety nets or for supplemental income (Scherr, 2003: 2 and Wondimu, 2008) where forest sector provide about 30 million jobs in the informal sector, as well as up to one-third of all rural nonfarm employment (Gobeze, et al, 2009).

The introduction of decentralized forest management Programme is also with the general objective of controlling forest degradation and achieving conservation of biodiversity on the one hand, while empowering communities to participate and improve their living condition on the other hand by developing formal management agreements with benefit-sharing clauses that act as incentives for local communities to manage the forest (Gobeze, et al, 2009). The approaches is promoted as one way of improving the livelihoods of rural communities (Tsi et al, 2016). Participatory forest management approach have in common the involvement of people who live in and around the forest in the management decisions that affect forest use and conservation (Gobeze, et al, 2009).Involving local community into forest management as primary stakeholders supposed to enjoy some benefits in terms of household level opportunities to meet their basic needs, however the government devoted limited right as the community does not supposed to make any decision about forest and not enjoying high value benefits instead they are supposed to benefit lower value (subsistence benefit).

The forest experts and community engaged in beliefs that the conservation gains are meaningful and appreciated however the productivity of the forest under PFM is low, management is restricted and an economic gain of the community is low which hinders the sustainability of forest management. The voice of participants in terms of what to generate from forest is dictated by experts as primary objective is to reduce deforestation not increasing income of households. The highland forests are the most suitable areas for human activities such as farming, grazing and harvesting non-timber forest products (Aerts et al., 2011). The Bale highland of Ethiopia is an example of one such unique and highly important ecosystem for survival of millions of people in Ethiopia and neighboring countries.PFM was introduced to Bale with the aim to improve forest resource and local community 
livelihood and currently there are about 120 PFM cooperative's In the zone (OFWEBB, un published).

\subsection{Specific objectives}

1. To identify the effect of participatory forest management on local community livelihood enhancement compared to non-PFM situation in Bale highland forest resource.

2. To identify and compare contribution of Participatory Forest Management for local communities' livelihood enhancement compared to before PFM situation in the Bale highland forest.

\section{METHODOLOGIES}

\subsection{Description of Study Area}

The main socio economic activity of Dinsho and Agarfa district Kebele are agriculture (animal husbandry and crop production). As the area is high land area, crop production and animal husbandry are ranking first and second economic activity, respectively. The major crops growing in the area are barely, wheat, potato, beans, lentils, garlic, cabbage; different vegetables. Both crop and animal production system are extensive production system and subsistence production. In addition, the community is also depending on forest products (DDFEDO, 2018 \&AWRLAEPO, 2018).The study was conducted in six selected forest villages namely; Abakara, Darahonsho, Kasomanso, Gofangira, Dinsho-02 and its part Zallokarari of Dinsho and Agarfa District of Bale Zone, Oromia region, south east Ethiopia. From these forest villages Abakara, Kasomanso and Zallokarari forest villages are forests without participatory forest management while the left three namely Dinsho 02, Gofangira and Darahonsho forest are under participatory forest management. The total households of these six villages are 3600 households including male and female headed households.

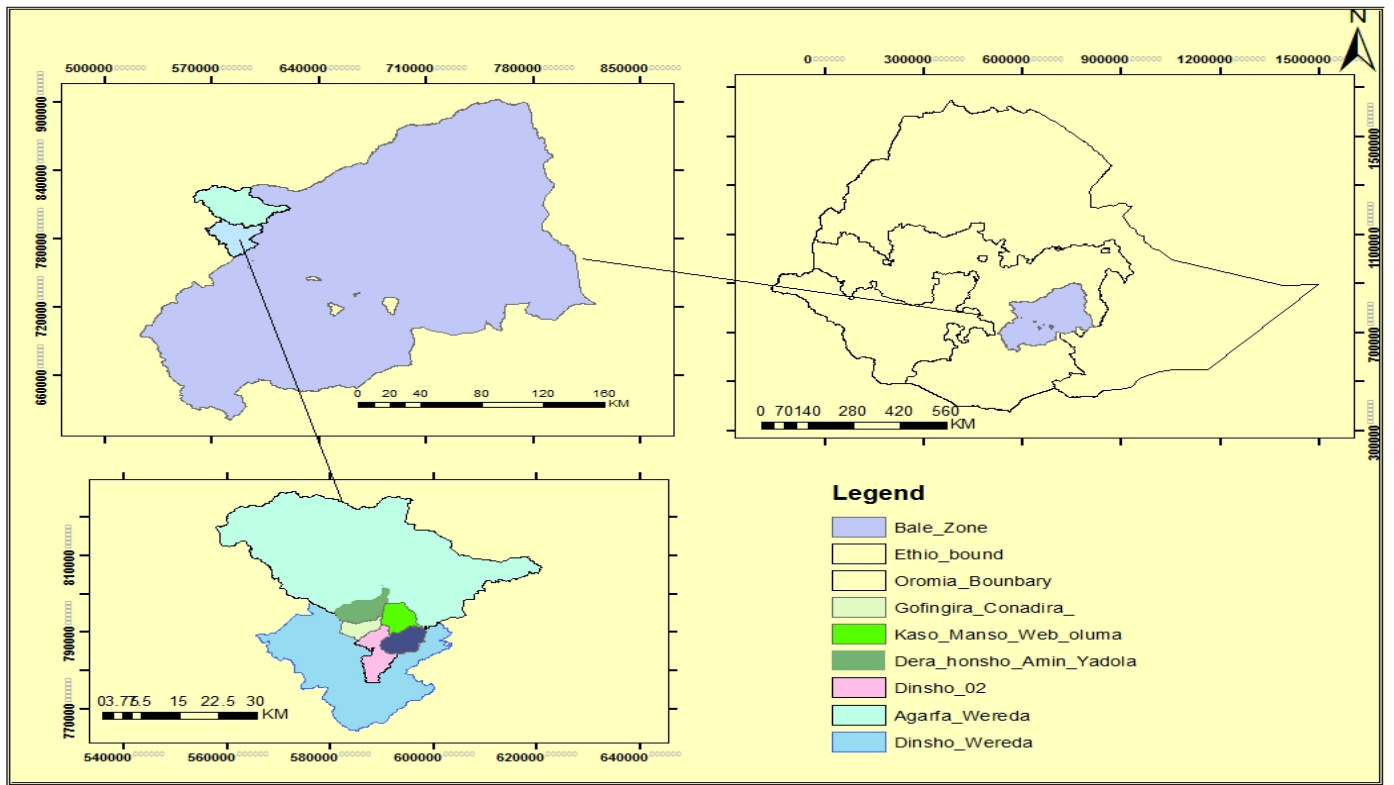

Source:- Authors work

Figure 1 Location map of study area

\subsection{Research design and Sampling procedure}

Exploratory and descriptive research methods were applied in selected areas and the roles of the Participatory forest management contribution to local livelihood explored. It is described in the context of the socio-economical contribution of the PFM. In addition the evaluation of the PFM situations of the livelihood explored and described in comparatively with before and after PFM and between members and non-members of PFM .Thus, before and after PFM of in three forest villages members and their livelihood status with very nearby non-members of PFM were identified .purposive sampling design employed in selecting survey sites in case of focus group discussion to allowed a variety of topics of the before and after PFM issues. Another requirement of the site selection were village pair in the same agro-ecological zone, similar in their livelihood and socio-economic patterns in order to minimize the other factors besides the forest management regime that could influence the comparison in selected study sites,

\subsection{Sample Size Determination}

The social survey and users of these forests was identified by collecting list of households from their respective Kebele administration office. Sample size for total household including Forest user group members and non- 
members that can access to selected forest site was determined by using probability proportional (Gupta 2002) $. \mathrm{n}=\frac{\mathrm{N}}{1+\mathrm{N}(\mathrm{e} 2)}$,

Where, $\mathrm{n}=$ indicates sampling unit, $\mathrm{N}=$ indicate total population, $\mathrm{e}=$ indicate the error that can be tolerated (which means it may take the value of 0.05). Accordingly there are about 3600 households in selected Woreda villages (Dinsho and Agarfa).Therefore from the formula the sample size found to be 360 household for this study. However 304 were properly filled and returned.

\subsection{Data sources}

Both qualitative and quantitative data were collected, these included; socio economic related and historical time series (before PFM). The before and after PFM social-economic contribution collected through questioner, interview focus group discussions(FGD) and key informant interview(KII). In addition, published and unpublished literatures of the previous reports, studies were also used as sources of data.

\subsection{Methods of data collection}

This study was based on both secondary and primary data sources.

\subsubsection{Secondary data collection}

The necessary and available data from PFM implementers which were in one way or another involved in PFM intervention and related activities were collected, The secondary data was collected from different relevant publications and reports in Websites, oromia forest and wildlife enterprise Bale branch, FARM Africa, Frankfurt Zoological Society ,MELCA mehiber and selected Districts of Bale Zone.

\subsubsection{Primary data collection}

Primary data were collected through household's survey, questioner, and key informant and compiled viz views of locals, socioeconomic benefits, effects/pressures of local peoples before and after PFM. The, users (members and non-members of PFM) of these forests were identified by collecting list of households from their respective Kebele administration office. The formal survey was focused mainly on the effects of PFM on local livelihoods in general and in terms of self-reported changes in income level, income sources and asset accumulations before and after PFM of members and non- members of PFM. The aim and purpose of the investigation was explained to selected participants in all the cases of data collection technique listed below.

\subsubsection{House hold survey}

Socio-economic data was collected through direct interview with the forest users specifically heads of households in selected villages. The structured questionnaire was designed to gather data on contribution of forest to livelihood of participants' in each selected villages. A pilot test of questionnaire was made before distributing the questionnaires. Amendment was made to exclude ambiguous and irrelevant questions. The questionnaires was prepared in English and translated into Afan Oromo languages. Respondents were well informed by the investigators that it was only used for the purpose of academic research and not for any other business or illegal activities beforehand.

\subsubsection{Focus group discussion and Key Informant Interview}

Local people who are reliant upon the local natural resources and who regularly interact with their local environment through their daily actives are often particularly aware of environmental changes and their effects. A question guiding on the perceptions of PFM cooperative members and non-members for roles of PFM contribution to livelihood was developed and translated to Afan Oromo language. One Focus group discussion and Key informant interview consisting $12 \& 8$ members respectively was chosen purposely since they have been identified as repositories of the knowledge in some previous study undertaken e.g. Participatory resource assessment (PFRA) and actors of PFM process directly and indirectly. Until saturation of information achieved the discussion was conducted with FGD and key informant comprising of zonal and District Forest Officers, members and nonmembers of FUGs, Village Chief, elders, women, NGO expert engaged in the area for the NR conservation activities, Village Councils and Village participatory forest management Committees (VPFMC). The FGDs was separately carried out with members and non-members of the local native people who have a strong connection with forest for their day-to-day needs to avoid any direct influences from third parties and to ensure that the data supplied by the participants are as Direct and reliable as possible. In-depth and useful discussions were held with the sectorial representatives about their roles and level of participation in the planning and implementation process of the Project, about their assessments/views on the significance of the Project's outcomes, especially in terms promoting income generating activities (IGAs) and improvement of livelihoods of the target project beneficiaries and associated shortcomings and limitations they have experienced and proposed future action.

\subsection{Method of Data analysis}

\subsubsection{Socio - economic data}

The responses of the key informant's questionaries' and records of Focus Group Discussions were coded and 
analyzed following the procedure outlined by Miles \&Huberman (1994). Accordingly, data was first coded in a form suitable for addressing research questions and concepts were identified and summarized. The formal survey data was cleaned, coded and analyzed with the help of the Statistical Package for Social Sciences (SPSS) 20 edition software and using both descriptive and inferential statistics. In order to assess the effect of PFM on livelihoods of local communities surrounding selected forest reserve, chi-square test and t-test at $5 \%$ level of significance, was used to show mean income difference between users and non-users, before and after PFM to test if there is a significant change on livelihoods of the communities as affected by the approach from their respective year of PFM implementation to 2018 for forest user groups (FUGs) members and non-members.

\section{RESULT}

\subsection{Socio-economic characteristics of respondents}

The questionnaires were distributed and collected back from participant and non-participant of in and around survey site of forest villages. Accordingly including $10 \%$ of additional questioners to compensate invalid and irrelevant respondents, 396 questioners were administered in selected areas of forest villages. Out of this, 304 were properly filled and returned in which 188 respondents were members of PFM whereas 116 were non-members. The Households demographic Information was collected and this comprises the personal attributes of the respondents including membership type like gender, age, level of education, total household family size, of respondents across areas surveyed. Respondents were grouped on the basis of gender, sex, membership types, level of education and family size. Result show that males headed respondent dominate females headed households and between the ages of 25-55years. Respondents educational status result show that most of the respondents in study areas attended primary education. Significant numbers of respondents were also continued up to secondary education while some of participants cannot read and write. Households family size of study area was between 03 and 4-6 persons per household, while some households family size was 6-10 and there is also household having more than 10 number of person per household.

For individuals Closeness to the forest edge, use appears positive and become negative as distance from the edge increases. Impacts also vary with level of education. The reported dependence and use increase with education. For low levels of education, the reported benefit are negative, but may be imprecisely estimated as stated by (Ranaivo et, al, 2016).

\subsection{Changes in food security status and household assets at village level}

According to respondents the dominant staple food of most family in study area were Barley (85.9\%), Barley and potato producers together $(12.8 \%)$ while potato contribute only $1.3 \%$ of household. In study area potato and other vegetable were serves for consumption and sale at large. The amount of food produced by $36.7 \%$ of household cannot feed their family so that they buy food to supplement their family due to small farm land owned by household $(98.2 \%)$.

The majority of the respondents reported reduction in vulnerability to food insecurity following an increase in population and introduction of Participatory Forest Management as households were unable to expand cultivation land. This has resulted in more demand for forest products as more people are competing for declining resources exerting increased pressure on forest resources. Some of the respondents indicated that, before PFM, they were facing serious food shortages although they can expand further land for crop cultivation and use forest resource intensively since they had not gained any technical training and agricultural inputs support from any source before the introduction of PFM to increase productivity. However after PFM introduced promotion of nonforest based livelihood activities like poultry production, beekeeping and the production of crops such as potato and the accompanying training received contributed slight increase in production and income levels.

\subsection{Access and Utilization of forest reserve}

Under the PFM initiatives, households will move from the open access status-quo to the proposed PFM which is common property regime. The implementation of the new participatory forest conservation approach provided the user groups in the study area legally recognized access to the forest products and services. Under Forest Management Agreement to prevent the loss of forest cover, households will be limited in their collection of timber and fuel wood collectively as this activity results in high effect (but high value for users) on forest products. Additionally Households was allowed to gather forest related goods and services like forest coffee, honey, bamboo and climbers those products collectively have relatively low effect (low economic value for users) on forest products. These would dictate the restrictions on the households for high effect (high economic value) forest products. It was necessary to assume that all high effect forest products were restricted in amount or type and some product even totally prohibited. The utilization of forest products is usually restricted and quotas for extractions are lowered to ecologically sustainable levels. Accordingly almost all of the survey respondents in the study villages reported a change in their utilization and access to forest resources since the establishment of the PFM. The access and utilization of forest resource high for both member and non-member before PFM while it becomes 
medium for members and low for non-members after establishment of PFM (figure 2).

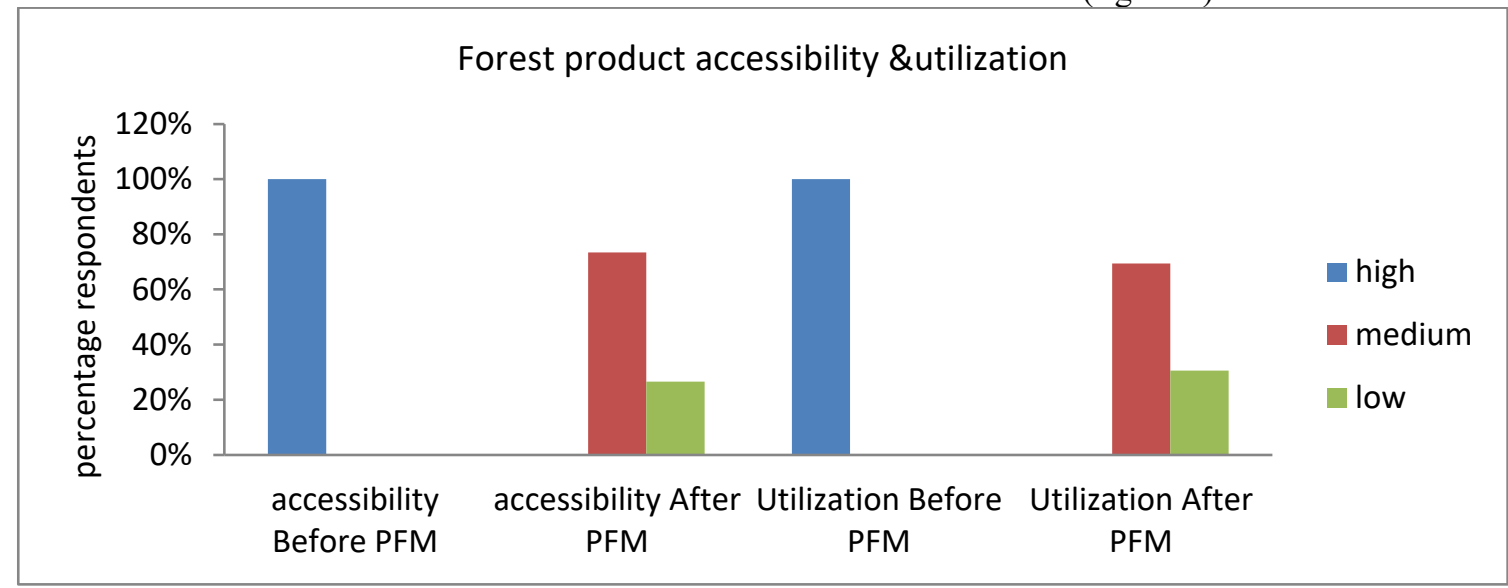

Figure 2 change in forest accessibility and utilization before and after PFM (respondent view).

In other way respondents were also asked and rank forest importance in livelihood support at household level, about $31.5 \%, 22.1 \%, 20 \%, 15.3 \%$ and $10.9 \%$ respondents were reported then ranked Fuel wood, Grass, Construction material, cultural service and medicinal respectively(table 1).

\begin{tabular}{|c|c|c|c|}
\hline Variable & Cases & Frequency & Percent \\
\hline \multirow{6}{*}{$\begin{array}{l}\text { rank according to important in } \\
\text { livelihood support beneficial at } \\
\text { household level }\end{array}$} & Fuel wood & 96 & 31.5 \\
\hline & Grass & 68 & 22.1 \\
\hline & Construction & 61 & 20.0 \\
\hline & Medicinal & 46 & 15.3 \\
\hline & cultural service & 33 & 10.9 \\
\hline & Total & 304 & 100.0 \\
\hline
\end{tabular}

The participants of all study sites (members and non-members) relied on forest as the source of domestic energy. Dependency on forest particularly fire wood is common in most rural areas of the country which are not connected to electricity system as the only sources of domestic energy. The dependency of Participants and nonparticipant on the resource for forest products such as firewood and charcoal utilization before PFM is complimenting with more non-wood-based uses such as animal dung and crop residue after PFM. Fuel wood is the dominant forest product collected by $99.6 \%$ users and $99 \%$ used the forest as a source of fodder for mainly cattle, sheep and goats. These households were entirely dependent on the forest for animal browsing and grazing of their respective forest site.

According to survey result of this study almost all household have access to forest and collects fuel wood from the forest once per week $(65.9 \%)$ while others collects $2-3$ times per week $(25.9 \%)$ and others every day (7.9\%). During the focus group discussion and key informant interviews, respondents mentioned that some people are using and collecting medicinal plants for either sell or family self-medications that forests are important source. In addition, this study showed utilization of more than one product with the majority of households member (nonmember) reporting being engaged in collection of fuel wood 98.6(81\%) before PFM and 98.6(84.3\%) after PFM, vegetables 70.9(98.8\%) before PFM and 71.5(27\%) after PFM, honey 42.5(31.3\%) before PFM and 19.9(13.3\%) after PFM, water and Pasture (99\%) for members and non-members respectively. The communities get access to grass illegally especially during dry seasons as long drought extended, forest become rescue center for within zone communities.

\subsection{Distribution system of forest products}

The forest reserve is divided into coupes to facilitate selective tree forest resources harvesting; harvesting is done following the strict harvesting and management plans, rules, and regulation; the strict laws and regulations include selective harvesting of trees for timber, only collecting dead wood for firewood, and harvesting of both timber and non-timber forest products should only be done upon acquisition of permit from the management committee at a cost for members only; furthermore, noncompliance with the laws and regulation attracts sanctions and penalties to both members and non-member's which conforms finding by(Vermeulen and Cotula,2010). This could be attributed to small levels of harvestable stock in the forest reserves due to the general declining trend in forest resources over the years although, respondents attributed the reduction in access to forest resources to the strict 
laws and regulations being enforced under the PFM Programme.

In the same way in study area forest products such as wood fuel, fodder, grass, and construction material are distributed from the community forest on the basis of their availability, which depends on the type and the area of the forest. During focus group discussion participants were asked about distribution system of forest and forest related products and all members have relatively good awareness on product utilization distribution system from their respective forest. Accordingly the distribution system was selected on the basis of provisions made in the operational plan of their agreement. Users of the community forest are given first priority in the distribution and are charged a reasonably low price so that every poor and disadvantaged household can benefit from the products of the community forest. Other forest products such as grass and fodder are distributed free of charge especially during drought to reduce their livestock death. The users need to use the forest products for household purposes, even when they are not using these products for commercial purposes. At the time of social and religious festivals, a natural disaster (e.g. drought), or any other unusual situation, the village forest committee can decide to provide more products particularly wood fuel and timber, free of charge to needy users as per the operational plan by notifying forest department. However in the case of forest without PFM there is no any operational plan for forest utilization and all type of utilization is free of any price with slight fear from Kebele administration. As a result human disturbance or uses are high in non PFM forest.

\subsection{Farmers Understanding of Historical Trends of forest products Conditions and utilization before and after PFM}

A number of studies and assessments conducted in Bale Zone specially related to the Bale Mountains National Park (BMNP) and the buffer zones reveal that the natural resources notably forest bio-diversities have remained under increasing pressure from a rapidly growing human population in order to ensure and maintain their livelihoods. The population of the zone is increasing almost linearly and as a result of this growth, existing settlements have been growing, and new settlements are appearing in previously unsettled and environmentally sensitive areas. This documented evidence is proved consistent with the views expressed during FGD and KIIs. The FGD participants were asked if they could recall the historical background i.e. about their past and present experiences and trends with respect to the status of the natural resources management and utilization by the communities or eco-system they are living in. In their feedback all the focus group participants reinforced by reiterating the above statements in one way or the other. Especially, the elderly women and men were very much illustrative in telling the story with regard to the observed real change of the forest resource and climate during their life time. The next age group, the adult and even the youth expressed their experience and events of the past from their childhood memory to the present. They are very much aware of the persisting conflict of interest in natural resources utilization and sustenance of rural livelihood leading to increased natural resources degradation. Farmers continued collecting a number of forest products even after the introduction of PFM. The products collected were poles, timber, firewood, farm implements and traditional medicine, etc. Firewood collection for own consumption slightly increased though the amount collected for sale declined significantly as was found out during discussions with key informants because it is not easy to collect firewood as it require to go far to get it. The respondent tried to remember and show the trend of forest and forest related products degradation by listing some the tree species status in past and present.

\subsection{Tree species Targeted for fuel wood before and after PFM}

Firewood and non-timber forest products (NTFPs) are essential for day-to-day livelihood strategies for rural households in many poor countries like Ethiopia; therefore improved access to and availability of forest resources directly and positively affect households' livelihoods. The participants used to collect both wet and dried fuel wood of any species before PFM. However they are allowed to collect only dry and naturally felled wood species after introduction of PFM. When listing benefits from forests during the study, firewood was either ranked first of all the listed benefits/products. Quite numbers of tree species were listed by the villagers as sources of fuel wood before and after PFM. The species that were mentioned includes Juniporus procera, Podocarpus falcatus hyginia abysinica, and Rapanea simensis and olea europaea. This suggests that these species are the most used indigenous species for firewood (figure. 3). The type of tree species targeted for fuel wood before and after PFM were also differs to some extent due to reduction of their availability in forest reserve as a result of heavy dependency in the past e.g. Juniporus and olea. 


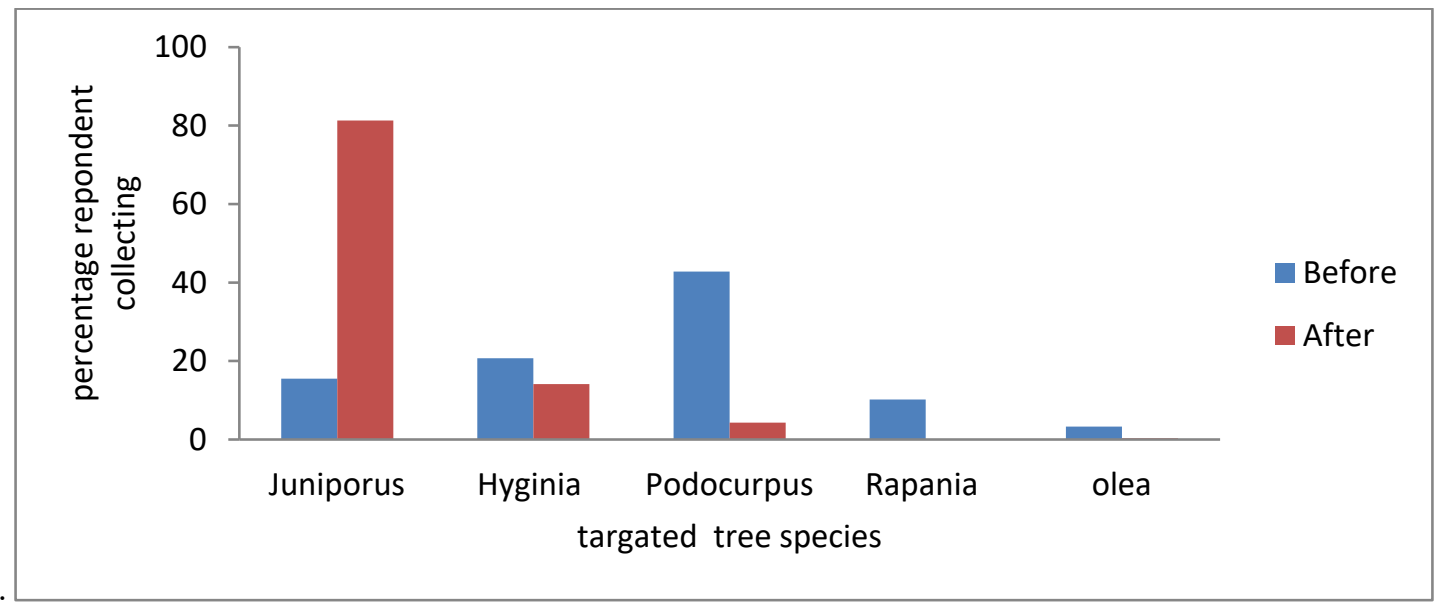

Figure 3 Tree species targeted for fuel wood by respondents before and after PFM.

The pattern of utilization inside the forest for different forest product changed following introduction of participatory forest management and reduction of forest resource product in non PFM forest. Before the introduction of PFM, all /large number of the respondent households used to graze their cattle freely in the forest, whereas only members and a few of the non-member respondents indicated that they still allowed their cattle to graze freely in the forest after PFM(figure 4) .

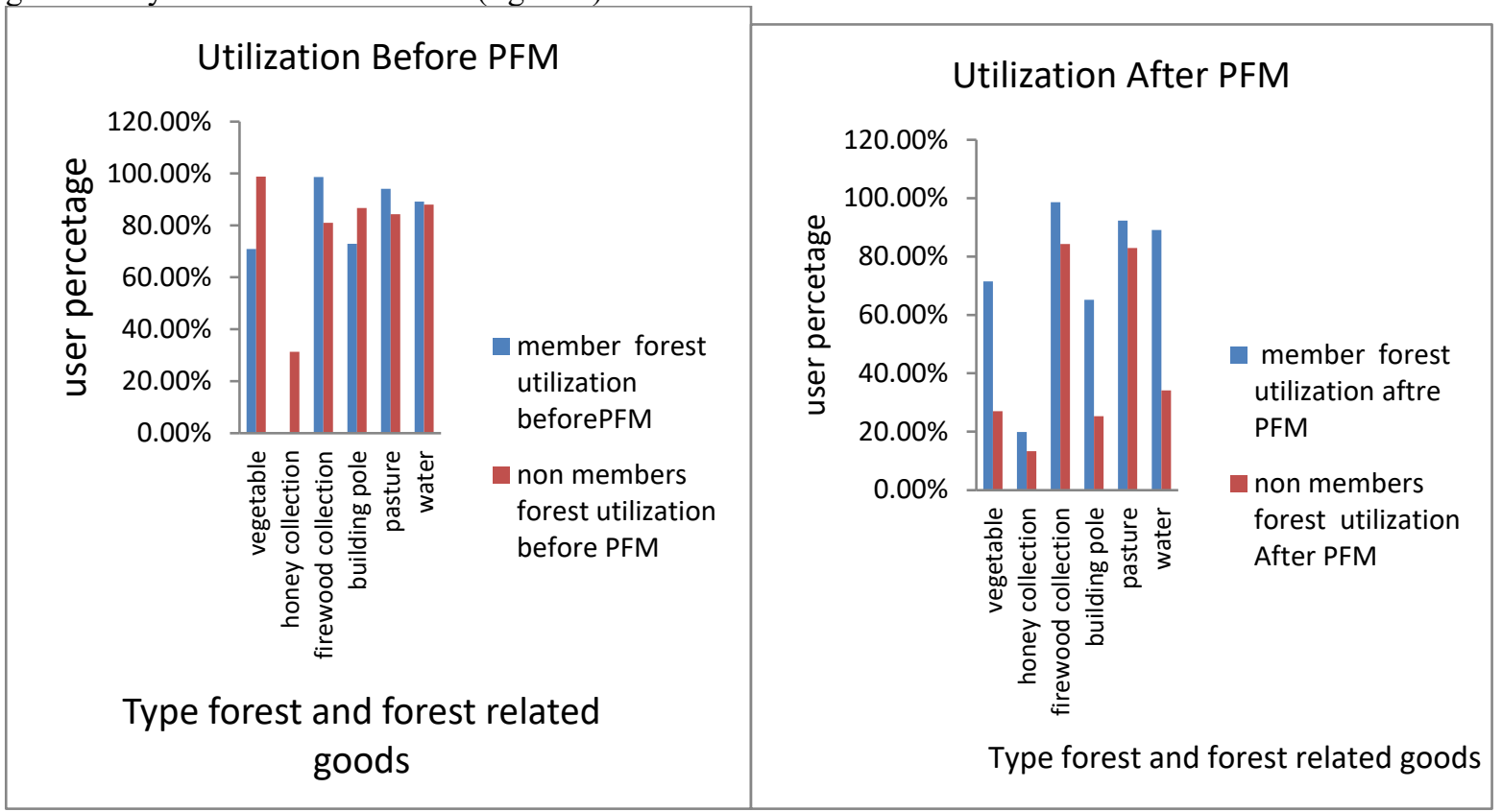

Figure 4 forest and forest related goods and services used by respondents before and after PFM from nearby forests.

\subsection{Natural forest product degradation}

The study areas were known with its natural forest, diversity and abundance of the species were high in the past. The economically, socially, medicinally, spiritually and environmentally valuable indigenous plant species such as Hagienia abyssinica, Juniperus procera, Maytenus spps, Hypercom revolutum, Schefflera abyssinica, Rapanea simensis, Erica arborea and others were abundant and well adapted in the area. However, their diversity and abundance have been decreasing rapidly with their respected values. In the studied villages of non PFM, households perceived a decline in the availability of forest products preferred for consumption. Households reported a decrease in forest cover which has led to decreases in the availability of forest products and forest related products. Local key informant try to recall and compare Forest condition and other related resources historical trend analysis of selected forest village and illustrated as some forest product have become rare considering the management regimes existed so far in the country(table 2). 
Table2. Forest condition and other related resources historical trend analysis of selected forest

\begin{tabular}{|l|l|l|l|}
\hline Information/resource & Haile Silassie & Derg Regime & EPRDF \\
\hline Firewood & High & Medium & Low \\
\hline Wild honey & High & Medium & No \\
\hline Hive honey & High & Medium & Low \\
\hline Timber & High & Medium & Low \\
\hline Medicinal plants & High & Medium & Low \\
\hline Soil exposure & Low & Low & Medium \\
\hline Grazing intensity & Low & Low & High \\
\hline Fire incidence & High & Low & Low \\
\hline
\end{tabular}

\subsection{House construction materials difference before PFM and after PFM}

In the study area, about $36.8 \%$ participant house constructions material is different from what they use before PFM while $63.2 \%$ still uses the same as before. Trees that are used for constructions of houses and roofing material are those which are durable, not easily attacked by termites, borers or wood decay fungi, repellent or toxic to termites and other wood-eating insects. The trees those are preferred for making implements such as axes and hoe handles, cooking sticks, bowls, for household use and for sale. For example they chiefly use Olea europaea as a fuel wood, Juniperus procera for construction purposes, Podocarpus falcatus for timber production through traditional way of logging, Allophylus abyssinicus and Acacia abyssinica for making charcoal and Teclea nobilis for making farming implements and sticks.

Another observed destructive habit of the local communities is their cutting of. The bark of Juniperus procera and Podocarpus falcatus trees is used for making traditional beehives and for making the roofs of the house and they always choose smooth trunked large trees. In Focus group discussion and key informant interview almost all interviewers reported that all Forest Goods are becoming difficult to find the preferred species, as they often have to walk long distances to harvest them. The Scarcity of certain tree species is forcing people to migrate to resource rich-areas or use less preferred species and this Selective harvesting \& other human disturbance has been reported to alter forest structure.

\subsection{Local people satisfaction in Participatory forest management regime}

The study found $72 \%$ of respondents indicated high level of satisfaction (very happy) and $24.4 \%$ respondents neither not happy nor satisfied, while $3.6 \%$ of respondents not satisfied (not happy), who satisfied were, mentioned in participation, conservation, development. Respondents neither not happy nor satisfied were, mentioned need some improvement in their ideas like grassing livestock in the forest rules and regulations. With regard to those mentioned not happy with PFM, need major improvement as PFM control their livestock from not grazing in the forest thus, they are after their animals and forest is not their concern. The prominent reasons is to utilize the forest resources exhaustively without control as accessibility and utilization is low and community livelihoods depend on livestock importantly so that at the time of famine and drought, they went to use grass, water and shade (figure $5)$.

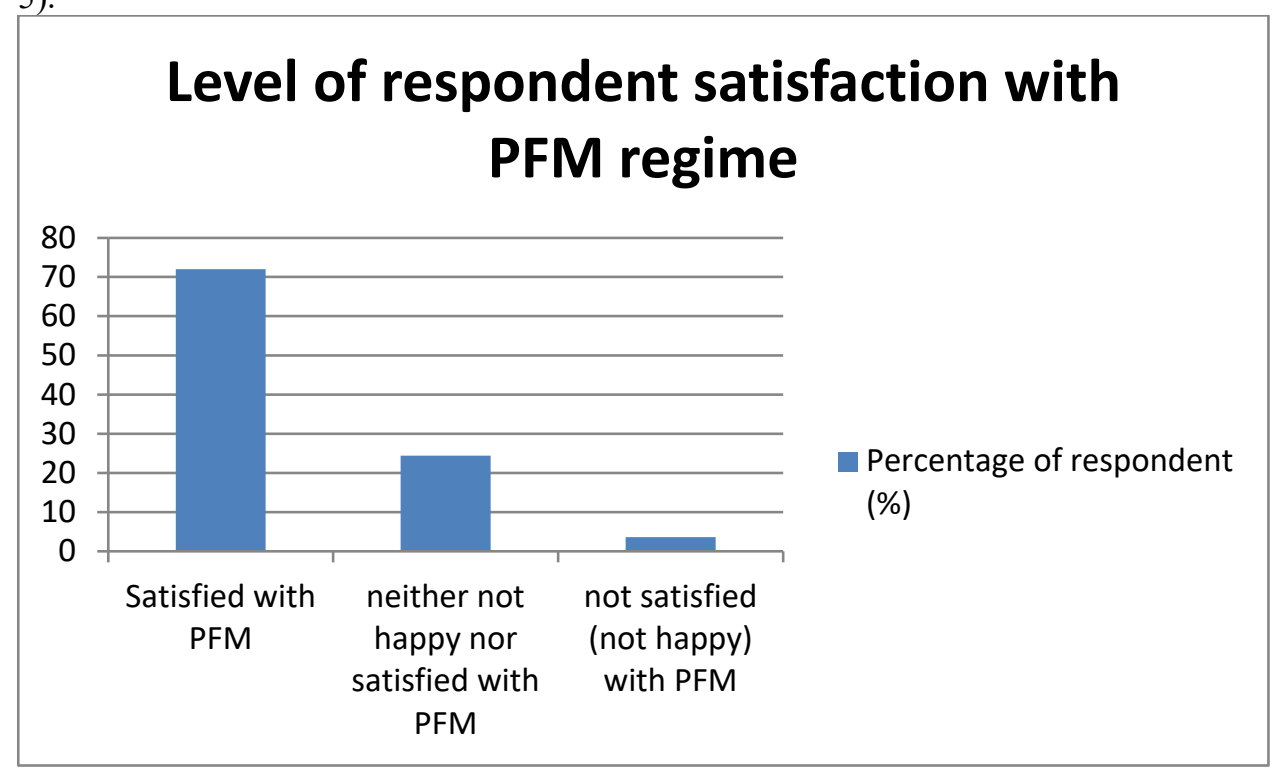

Figure 5.Level of respondent satisfaction with PFM regime 


\subsection{Participants Perception of livelihood condition}

According to respondents compared to the years before PFM the overall condition has improved a bit( $45.9 \%)$ to the livelihood of local community though, few groups still reported much improvement (6.9\%) while others reporting that the approach did not have any effect and even worsened their livelihood to some extend $(23.9 \%, 23 \%$ respondent respectively). Additionally according to respondents of study area the general benefits of PFM viewed in terms of sustainable utilization of forest product $(24.3 \%)$ and introduction of income generating activities $(6.2 \%)$. Furthermore in their view the expected beneficiary from the forest were mostly participants of the regime $(55.6 \%)$, while all villagers $(31.9 \%)$ and non-members also have share $12.5 \%$. This difference in number of households perceiving a positive effects and those perceiving negative effect could suggest inequalities in benefit sharing. This supports the findings in study result of [Vermeulen and Cotula, 2010] that found that a majority of participants in PFM perceive benefit distribution as unfair and that only a few influential members of the community, for example, committee members and chiefs, share the benefits from the forest itself and PFM implementers. The probability of perceiving a positive overall impact of PFM on livelihoods is 55\% higher for households in PFM programme compared to those in non-PFM and 52\% higher for households that perceive better access to and availability of firewood (figure 5).

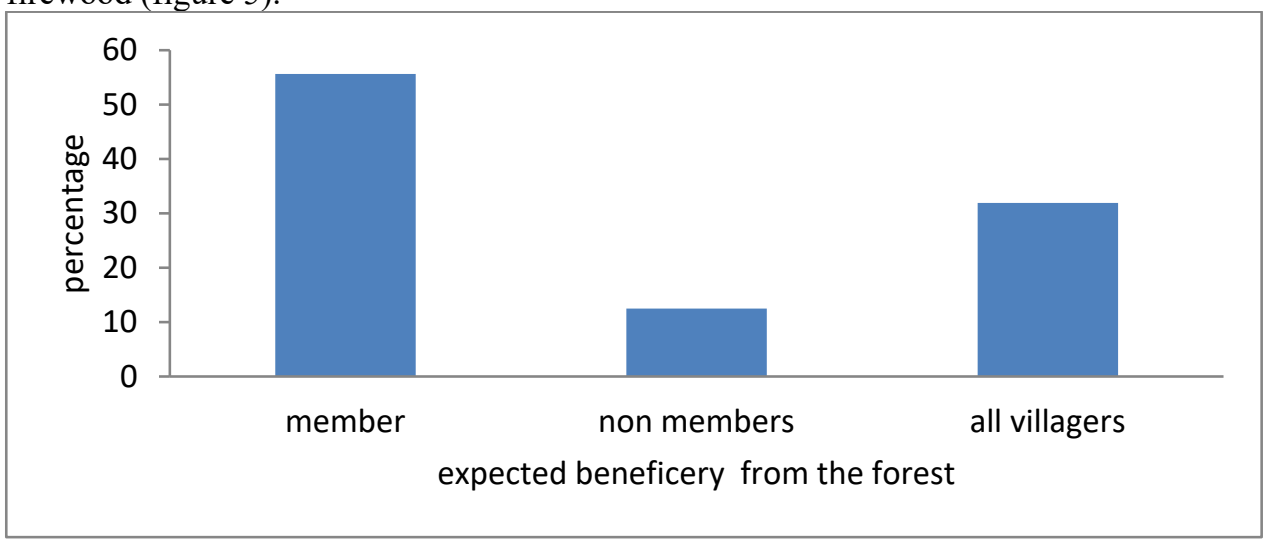

Figure 5 .The most expected beneficiary from the forest according to respondents view.

\subsection{Socio-economic significance of PFM at village level}

The household Socio-economic characteristics of PFM members and non-member households do not differ much. In contrast, some site characteristics clearly differ: members' have more forest area, a greater percentage of forest area. The estimated effect of PFM on livelihood in their view is positive, but too small. Available reports indicate that PFM implementers, in collaboration with involvement of relevant government offices, has conducted baseline assessment for identifying alternative schemes for augmenting household income for targeted group in the project area.The findings of the baseline assessment indicated that environmental friendly IGAs such as the production of highland fruits like apple ,beekeeping activities non-timber forest products (NTFP), sheep fattening and rearing were possible areas of interventions identified as environmental friendly interventions that can help generate household income mainly of the poor women and unemployed youth group. Approximately, 29\% of respondents indicated that the program has helped them to attain new income sources, such as wage labor during enrichment plantation in forests; income generating activities, for example, NTFP sales, firewood sales, pottery (clay pots) sales, sheep fattening and raring, bee-keeping, and highland fruit; Fuel saving stoves and indirect benefits in the form of dry season grazing in forest.

Similarly, there was an increase in the number of households accessing loans and saving in the local village banks since the program started. Therefore suggesting that communities not only measure perceived benefits in terms of economic benefits but also measure perceived benefits in social and noncash benefits which contradict the statement of Ellis (2000) that suggested communities perceive the benefits of forest co-management programs as minimal because they only measure benefit in terms of monetary or tangible economic benefit. Access to new income sources increases a household's probability of describing the overall program impact as positive by approximately $72 \%$. According to Vyamana (2009) and Gobeze (2009), this is expected because access to new income sources can potentially translate into increased income levels and improved livelihoods. Furthermore, Wool cock (2001) indicated new income sources may diversify household livelihood sources hence reducing household's vulnerability to shocks and stresses (e.g., failure in crop production). The income generating activities initiated by the program implementers are forest-based and group-based; hence it is plausible that the probability of accessing new income sources is higher for member households.

The PFM implementers has been providing livelihood support of pressure reducing measures from natural resources in the form of Income Generating Activities (IGAs). As a means of building household asset provision 
of fattening and breeding sheep to some most needy households (largely to women) was the key strategy being implemented in the study areas. In addition, the distribution of fuel saving stoves and organizing women in the production of the Stove is also considered as one another form of livelihood support with the ultimate goal of contribute to the reduction of pressure from the surrounding forest resources. Following the entrepreneurships trainings, reportedly about $92 \%$ of the trainees had preferred sheep fatting and herding as promising IGA. On this basis different organizations distributed a sheep for the trainees. Monitoring report indicates that the support has benefited in terms of gaining cash income from the raring and sales of the fattened sheep (25\%).

The IGA beneficiaries participated in FGDs have witnessed that the support of breeding sheep to the needy households has been beneficial in terms of augmenting their incomes to cover their expenditures, such as school fees $(20 \%)$, children clothing(12\%), and for sustenance in some cases(3\%). Selected FGD participants told their story of selling sheep to complement short term cash requirements and/or to build their assets for meeting sustained household needs and the family presently has owned cow milk from the income earned from sheep production. .

With the aim to reduce pressure from forest and biodiversity resource, supply of energy saving stoves to the households living around the selected was one of implementers interventions implemented. The need for this product was brought forward based on a house to house baseline assessment and community consultations. In order to produce and supply the stoves participants were trained unemployed youth group and model women in the community. Targeted beneficiaries were community members who actively participated on PFM forest conservation, those of low income families who could not able to buy the fuel saving stove, female-headed households, women who had health/asthma problems from using the traditional stove and those who had large family members with higher fuel wood need.

During the FGD, non-members respondents reported a decrease in the adequacy and availability of biomass fuels. They indicated that, the main source of energy for Households cooking is largely from the crop residue eucalyptus tree planted at homestead in order to cope with the problem. The feedback from the FGD participants regarding the contribution of fuel saving stove (FSS) to the reduction of pressure on forest resources was consistent with the progress. During the discussion women participant also witnessed, among other things, the additional value of the stoves in terms of protecting them from indoor pollution which was among the main cause of health deterioration of women and the household members in general and saved them from medical expenses.

Social capital represents the social resources upon which people draw in pursuit of their livelihood objectives which are developed through level of networking in the village from formal organization to informal working, connectedness, and relationships of trust, reciprocity and exchange. It involves networks among the community and how well villages are able to negotiate with external environment. The trust and relationship of member to member and member to forest department and other different supporting NGOs in participatory villages is comparatively good than that of the people of non- participatory project villages. This was because, in project villages, meetings were held and staff from the forest department and supporting NGOs attended these meetings, thus increasing the chances of interaction with the member community. The study observed that due to intensive training and community activities, a social network occurred among participants and local communities as well. Moreover, participants acquired skill and knowledge had an effect on the social capital, such as building relationship and encouraging self-capacity with the participating people.

Impacts on financial capital were evaluated in terms of perceived changes in income sources, income levels, ability to access loans, employment opportunities, and ability to accumulate savings. We assessed physical capital at both community and household level. Local communities surrounding forest of study site earn their livelihoods from subsistence agriculture, rearing livestock, small scale business and forest related activities. Agricultural products like Barley, wheat, potato, and other vegetables production have dual function of being both a household food and cash crops. Potato is usually cultivated for commercial purposes. The relative average yearly gain and contribution to general livelihood of cash crops 48(46) \%, Bee keeping 12(11) \% forest goods 19(15) \% was slightly decreased after PFM while increased for the case of livestock 22(28)\%. The used Paired-t-test and chisquare test analysis of the incomes derived from different forest products before and after PFM as well as between members and non-members of PFM revealed a significant difference $(\mathrm{P}<0.05)($ table-3). 
Table 3 Result of Paired Samples Test of economic gain from income generating activities before and after PFM in Ethiopian Birr.

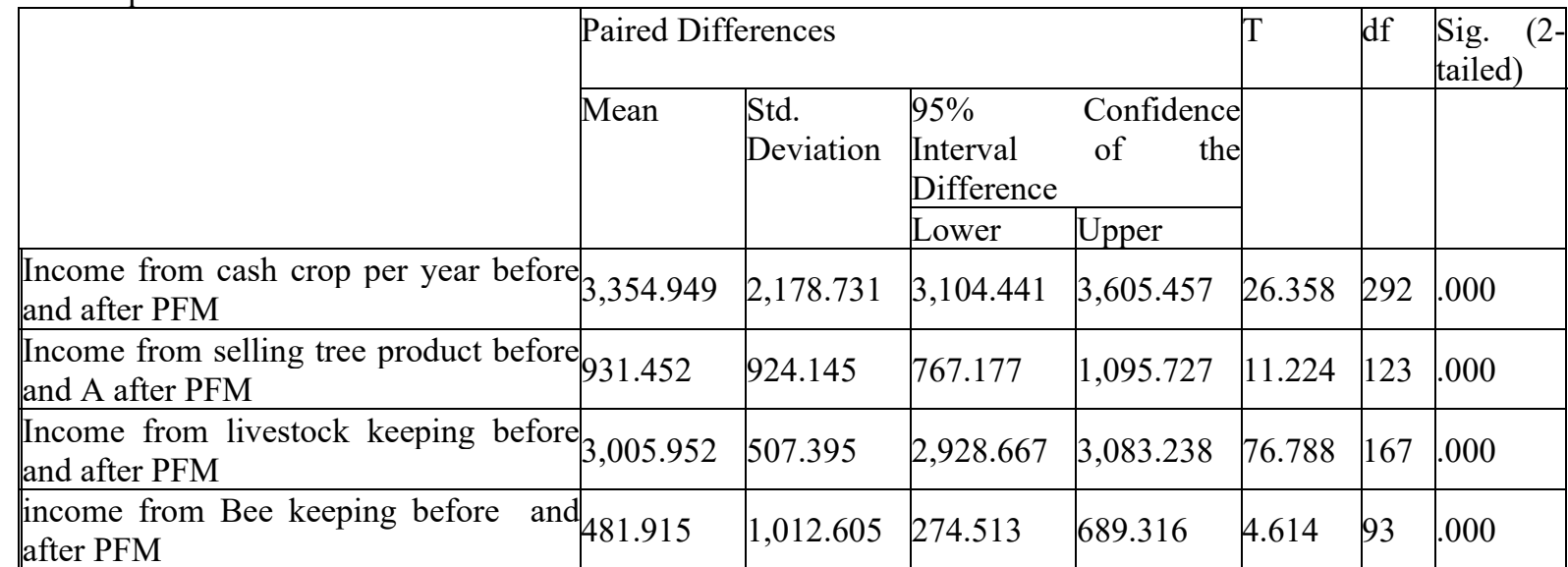

Households in Non PFM area and non-members of the association derive the lowest average forest value. Forest products have significant share of household income after agriculture and livestock. Income from forestry includes that from the sale of timber/logs, wood fuel, and non-timber forest products like honey and bamboo.

During focus group discussion expert of forest department and village forest committee members reported that the committee collects non-forestry funds such as registration fees from users, membership fees, and donations from various organizations such as non-government organizations where there is hunting of wildlife. These funds are utilized for different community development and improve such as community buildings health services, school support and facilitation of forest management meetings. The revenue from ecotourism do not exist yet, but the process to institutionalize ecotourism is ongoing (e.g. Darahonsho). Additionally it is important to mention that, Darahonsho village have been selected/ proposed as pilot village for carbon funds, for the first phase but not started yet as well. Accordingly PFM village forest reserve are hoping more revenue from tourists and participated in a REDD pilot project to be paid compensation for avoided deforestation and has increased the motive for community conservation effort.

\subsection{Benefits from improved human capacity development at village level}

Based on the finding of the study assessment, different PFM implementer's has conducted a series of training sessions. In all study villages of under participatory forest management forest committees and members reported to have benefiting from various training in relation to forest management. Specific training aspects received by members included financial management and selected business options such as; sheep fattening, bee keeping, honey production techniques, Production of fuel wood saving stove and entrepreneurship skills. The result of this study also showed the increased chance of participating in different activities (figure-6).

This indicates that the participatory forest management regime is improving human capital through various training which was not provided before the existing management regime (PFM).

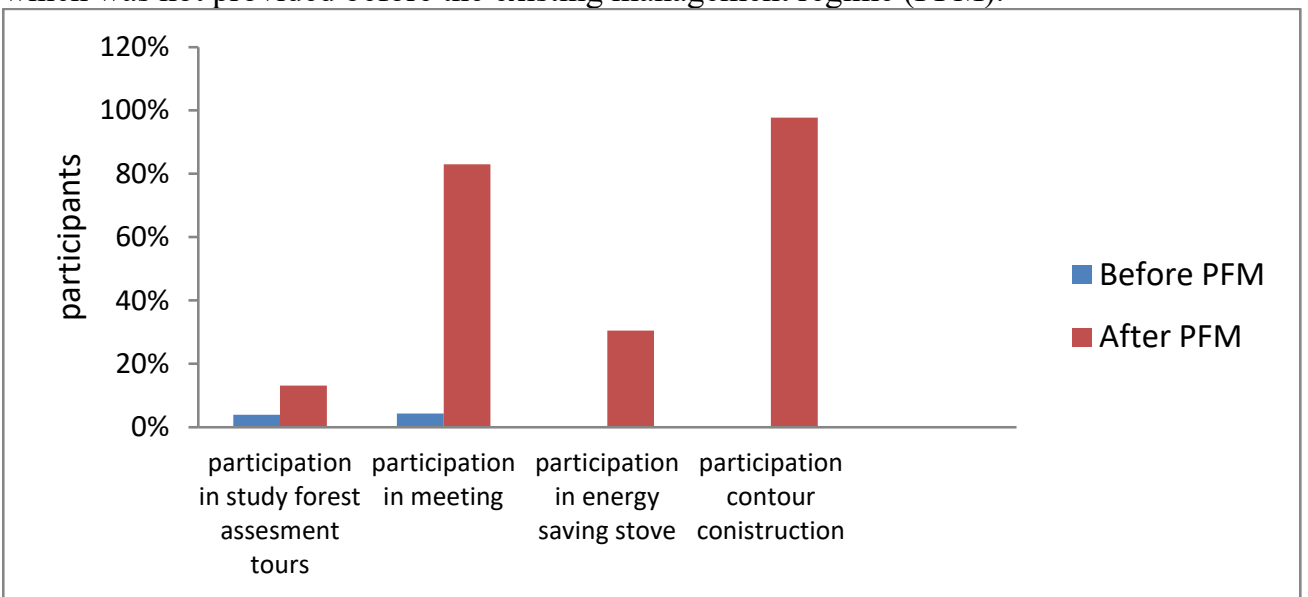

Figure 6. Awareness and capacity building activity for Household before and after PFM.

The overall aim of the trainings was to improve their capacity in forest management and empower adjacent communities through environmentally and socially sustainable utilization of forest resources. This was done through collaboration with OFWE staff, Woreda land and environment protection NGO like Frankfurt and Farm Africa. 
Different governmental and non-governmental organizations (NGOs), particularly FARM Africa, MELCA Ethiopia, Frankfurt zoological society and oromia forest and wildlife enterprise, have been facilitating and offered intensive community based training and capacity building in the area which played a valuable role in the knowledge and skill development of members. The study also observed that the above mentioned Governmental and non-governmental body gave the highest priority to capacity building, with the intension that the illiterate community were unable to start any alternative livelihood program unless they were fully trained. In their view Trainings can enhance skills and skills might have significant effects on the participants' attitude and perception of living, as well as forest conservation.

\section{DISCUSION}

As described in several PFM project documents, one of the rationales for introducing the PFM arrangement was to ensure sustainable management of forest resources while improving the socioeconomic condition of forestdependent local communities. As a livelihood development component, the implementer's established a tree nursery, initiated poultry and sheep husbandry and provided micro-credit to PFM members. The livelihood support also included capacity building on deferent forest management and livelihood improvement ideas which is also supported by the concept identified by Ayana,et,al (2015). Human capital comprises education, knowledge and skills, health, and food security, in this paper we present impacts on human capital based on perceived changes in training and knowledge development before and after the implementation of the programme between members and non-members. The specific training aspects received by members includes bee keeping, tree seedling rising, fuel wood saving stove making and entrepreneurship skills Shimizu (2006) also identified the same concept. (Baumann and Sinha 2001) and Fisher(2004),described human capital in terms of food and nutrition can be reflected in the assessment of natural capital through changes in access to and availability of forest products including fruits and vegetables and financial capital through income effects.

A majority of community members perceive that training and skill development activities have increased since the programme started. Although the programme does not provide formal education, it contributes to the development of human capital, by facilitating training in forest management and income generating options. This training program on different aspects was able to create leadership and build a strong network among participants in which they could work as a team and ensured capacity buildings so they were able to easily improve household income. The concept which is the same with study result of Ali, et.al, 2007, Tadesse et al. 2017 that showed training enhances skills that might have significant effects on the participants' attitude perception of living and forest conservation to easily improve household income.this indicates that PFM regime is improving human capital of members than that of non-members through various training which was not provided before the existing manegemnt regime (PFM) and currently to non- members of the regime.This result concurs with research finding of Gobeze et al, 2009 and Mammo et al .2017 which conc-lude as training on different aspects scored improvement of participants' human capital and Niesenbaum et al .2005, Vyamana ,2009,Maharja et al,.2009,Sabsebew(2010) conclusions that reflected deteriorating trend for non-participants due to deference in forest management among the two groups.

The program also facilitates and enhances the development of social capital through establishment of village committees and initiating regular community meetings, where issues relating to forest management and other developmental issues are discussed. The committee meetings allow for regular interaction with government forest staff and other stakeholders, hence increasing their social network base and ability to contribute to forest policies that affect their livelihoods (Maharjan et, al.2009). Furthermore, social capital enhances human and financial capital among households since communities are able to form village banking groups and further access loans from the banks

The trust and relationship of member to member and member to forest department and other different supporting NGOs in participatory villages is comparatively good than that of the people of non- participatory project villages because the meeting held with/by different forest sectors increasing the chances of interaction with the member community. The concept of this study finding concurs with the idea stated by DFID 2001 which showed that the trust and relationship of people to the forest department in participatory project villages is comparatively higher than that of the people of non- participatory project villages. The observed intensive training and community activities, a social network that occurred among participant and local communities as well could contribute indirectly to peoples livelihood by providing social benefits which is also the same with the result of Amente,(2006) identified.

More over participants acquired skill and knowledge had an effect on the social capital such as building relationship and encouraging self capacity with participating people. This result is the same with finding of Matiku, (2013) and Tadesse (et al.2017) which stated as PFM approach has showed a remarkable improvement in social assets. 


\section{CONCLUSION AND RECOMMENDATION \\ 5.1 Conclusion}

The main objective of PFM initiation is to contribute to the revival and restoration of biodiversity and local community livelihood through effective participation of the communities. The strategy adopted, among others, include provision of livelihood support for the natural resources dependent community while empowering them for sustainable management of the forests. Through this survey, it has been possible to gather feedback from the interviewed community representatives evidencing that the IGA initiated and supported by PFM implementers has been augmenting household income of the beneficiary communities slightly while also contributing to the reduction of pressure on the forests.

The major challenge remains to be creating a mechanism to prevent the low income members of the PFM members not to be subjected into deep poverty and forced to exploit the existing natural resources they vowed to protect. The need to support this group of the society is directly attached to the health of the forest and ecosystem in general. Therefore, establishing a system where IGA options could be means of augmenting their sustenance and build their resilience against both climate and asset shocks is key element to be considered.

Agriculture (mixed farming and livestock rearing) is the main occupation of the community in the research woredas. This has resulted in the expansion of agricultural land and new settlements areas. Unchecked population growth and poor productivity of crop and livestock has remained to be the driving force. Reviews and perceptions by the FGD participants reveal that series of environmental sensitization, entrepreneurship training, awareness raising and experience sharing activities undertaken by PFM implementers had been instrumental in enhancing the communities' participation resulting in achievement in the restoration and protection of the present forest and revival of bio- diversity in their areas. It has also been learnt from the FGD and questioners that the implementers supported IGA of sheep rearing has benefited in terms of meeting their cash needs from sales of incremental production.

\subsection{Recommendations}

- IGA options like Sheep can turn in to cash as a safeguard against crises or for meeting the immediate sustenance need. Saving in terms of increasing the number of herds could be of high risk. As there are reported cases, the overall return could turn low. In light of this and considering the communities preference, the result would suggest for consideration by all supporting actors:

- Introduction of improved sheep breeds,

- Awareness raising of beneficiaries for optimizing production by limiting the size of herd, and

- Organize or strengthen saving and credit scheme of the beneficiaries in partnership with the relevant government organizations.

- It is understandable that IGA interventions need to continue to focus on the links between biodiversity conservation and community livelihood. In the context of limited forest related products however, the need to consider the links in supporting the agricultural productivity as a means of for income improvement and to contribute in building productive household assets.

- As indicated in the concluding remark above, PFM approach would have an impact on the conservation of forests by partly complementing the need of farmers to increased yields from the use of improved varieties of locally adaptable potato and other vegetable seeds. In this connection the study would stress for the need to ensure that effective extension service are provided for adaptation of the recommended agronomic practices as well as regular follow up and monitoring in collaboration with the agricultural office.

- Promotion of agroforestry and plantations in homesteads is an important intervention because of the land scarcity issue in the 6 villages surveyed. The aim of this intervention is to enhance the capacity of farmers in agricultural practices and land use management through agro forestry technologies. Increasing productivity of farm land through introducing agroforestry practice such as highland fruits (e.g. apple), encouraging ecologically adaptable cash crops like garlic, potato and improving the management of the animals.

\section{REFERENCE}

Aerts, R., Van Overtveld, K., November, E., Wassie, A., Abiyu, A., Demissew, S., Daye, D.D., Giday,

Ali, T., Ahmad, M., Shahbaz, B. and Suleri, A., 2007. Effect of participatory forest management on vulnerability and livelihood assets of forest-dependent communities in northern Pakistan. The International Journal of Sustainable Development \& World Ecology, 14(2), pp.211-223.

Amente, G., 2006, March. Integrated and participatory forest management in the Bale mountains of Ethiopia. In International Symposium towards sustainable livelihoods and ecosystems in mountainous regions (pp. 7-9).

Ayana, A.N., Vandenabeele, N. and Arts, B., 2017. Performance of participatory forest management in Ethiopia: institutional arrangement versus local practices. Critical Policy Studies, 11(1), pp.19-38. 
BoFED.(2016). The National Regional Government of Oromiya Bureau of Finance and Economic Development, Physical and Socio Economic Profile of Bale Zone and 21 Districts, 2016, Finfine

Dev, O.P., Yadav, N.P., Springate-Baginski, O. and Soussan, J., 2003. Impacts of community forestry on livelihoods in the middle hills of Nepal. Journal of forest and Livelihood, 3(1), pp.64-77.

Ellis, F., 2000. Rural livelihoods and diversity in developing countries. Oxford university press.

Fisher, M., 2004. Household welfare and forest dependence in Southern Malawi. Environment and Development Economics, 9(2), pp.135-154.

Gobeze, T., Bekele, M., Lemenih, M. and Kassa, H., 2009. Participatory forest management and its effects on livelihoods and forest status: the case of Bonga forest in Ethiopia. International forestry review, 11(3), pp.346358.

Islam, K.K., Sato, N. and Hoogstra, M.A., 2010. Poverty alleviation in Bangladesh: the case of the participatory agroforestry program. International Forestry Review, 12(5), pp.413-413.

Kenea, W., 2010. Rural livelihood, land management and biodiversity: Community participation for biodiversity conservation (Doctoral dissertation).

Maharjan, M.R., Dhakal, T.R., Thapa, S.K., Schreckenberg, K. and Luttrell, C., 2009. Improving the benefits to the poor from community forestry in the Churia region of Nepal. International Forestry Review, 11(2), pp.254-267.

Maharjan, M.R., Dhakal, T.R., Thapa, S.K., Schreckenberg, K. and Luttrell, C., 2009. Improving the benefits to the poor from community forestry in the Churia region of Nepal. International Forestry Review, 11(2), pp.254-267.

Matiku, P., Caleb, M. and Callistus, O., 2013. The effect of participatory forest management on local community livelihoods in the Arabuko-Sokoke forest, Kenya. Conservation and Society, 11(2), p.112.

Missanjo, c. M. (2015). effect of Participatory forest manegement on tree species abundoncy and diversity. journal of ecology and environmental science .

Niesenbaum, R.A., Salazar, M.E. and Diop, A.M., 2005. Community forestry in the Mayan biosphere reserve in Guatemala. Journal of sustainable forestry, 19(4), pp.11-28.

Rasolofoson, R.A., Ferraro, P.J., Ruta, G., Rasamoelina, M.S., Randriankolona, P.L., Larsen, H.O. and Jones, J.P., 2017. Impacts of community forest management on human economic well-being across Madagascar. Conservation Letters, 10(3), pp.346-353.

Sebesew Yideg.(2010) Escaping Poverty's Grasp: A WAJIB Approach For Environmental Conservat ion and Eco Tourism Development to Enhance Rural Livelihoods. A Case Study on Int-egrated Forest Management project (IFMP) Adaba-Dodola. Addis Ababa University, Ethiopia

Shimizu, T., 2006. Assessing the access to forest resources for improving livelihoods in West and Central Asia countries. FAO LSP WP, 33.

Sinha, S. and Baumann, P., 2001. Linking Development with Democratic Processes in India: Political Capital and Sustainable Livelihoods Analysis. Natural Resource Perspectives, Overseas Development Institute, 68, pp.25 .

Tadesse, S., Woldetsadik, M. and Senbeta, F., 2017. Effects of participatory forest management on livelihood assets in Gebradima forest, southwest Ethiopia. Forests, Trees and Livelihoods, 26(4), pp.229-244.

Tsi, E.A., Ajaga, N., Wiegleb, G. and Mühlenberg, M., 2008. The willingness to pay (WTP) for the conservation of wild animals: Case of the Derby Eland (Taurotragus derbianus gigas) and the African wild dog (Lycaon pictus) in North Cameroon. African Journal of Environmental Science and Technology, 2(3), pp.051-058.

Vermeulen, S. and Cotula, L., 2010. Making the most of agricultural investment: A survey of business models that provide opportunities for smallholders. Iied.

Vyamana, V.G., 2009. Participatory forest management in the Eastern Arc Mountains of Tanzania: who benefits? International Forestry Review, 11(2), pp.239-253.

Woolcock, M., 2001. The place of social capital in understanding social and economic outcomes. Canadian journal of policy research, 2(1), pp.11-17. 